\title{
Impact of transition on quality of life in patients with congenital adrenal hyperplasia diagnosed during childhood
}

\section{Anne Bachelot ${ }^{1,2}$, Magaly Vialon', Amandine Baptiste ${ }^{3}$, Isabelle Tejedor', Caroline Elie $^{3}$, Michel Polak, ${ }^{4,5}$, Philippe Touraine ${ }^{1,2}$ and the CRMERC study group*}

'Department of Endocrinology and Reproductive Medicine and Centre de Référence des Maladies Endocriniennes Rares de la croissance et Centre des Pathologies gynécologiques Rares, AP-HP, IE3M, Hôpital Pitié-Salpêtrière, ICAN, Paris, France

${ }^{2}$ UPMC Univ, Paris, France

${ }^{3} \mathrm{AP}-\mathrm{HP}$, Clinical Research Unit Paris Descartes Necker Cochin, Paris, France

${ }^{4}$ Department of Pediatric Endocrinology, Gynecology and Diabetology, Centre de Référence des Maladies Endocriniennes Rares de la Croissance et Centre des pathologies gynécologiques Rares, Hôpital Universitaire Necker Enfants malades, Paris, France

${ }^{5}$ Université Paris Descartes, Paris, France

*(details of CRMERC study group is given in the Acknowledgements section)

Correspondence should be addressed to $P$ Touraine

Email

philippe.touraine@aphp.fr

\begin{abstract}
Background: Health-related quality of life (QoL) in adult patients with congenital adrenal hyperplasia (CAH) has been variously reported. However, there is no study evaluating the impact of transition on quality of life.

Methods: Adult patients with classic or non-classic CAH diagnosed during childhood $\mathrm{CAH}$, born between 1970 and 1990, were recruited from the registers of Pediatric departments belonging to the French reference center for endocrine rare disease. Primary end point was the QoL (WHOQOL-BREF).

Results: Seventy-three patients were included in the study, among them 59/73 were transferred to adult endocrinologist by their pediatricians for transition. WHOQOLBREF scores were similar between patients with or without transition to specialist adult services, except for environment dimension score, which was slightly higher in $\mathrm{CAH}$ patients without transition. However, $\mathrm{CAH}$ patients with a regular follow-up had a better physical health, psychological health and environment score and item global QoL than the group without regular follow-up after transition.

Conclusion: Regular medical follow-up in adulthood is associated with the transition between pediatric and adult care and is associated with better QoL in adults with $\mathrm{CAH}$.
\end{abstract}

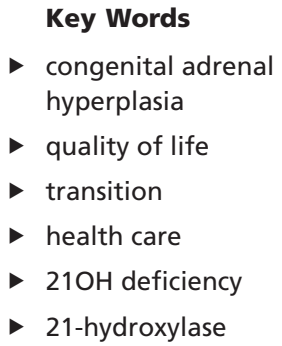

Endocrine Connections (2017) 6, 422-429

\section{Introduction}

Transition is defined by the Society for Adolescent Medicine as a 'purposeful, planned movement of adolescents and young adults with chronic physical and medical conditions from child-centered to adult-oriented health care system' (1). Congenital adrenal hyperplasia $(\mathrm{CAH})$ is a lifelong condition. CAH is classified according to symptoms, age of presentation and genetics and is usually divided into two forms: the classic or severe form and the non-classic form (2). Pediatric endocrine care is delivered through specialist services, and the recommendation is that patients with $\mathrm{CAH}$ should remain within specialist services as adults. Management of adolescents http://www.endocrineconnections.org DOI: 10.1530/EC-17-0094 (c) 2017 The authors Published by Bioscientifica Ltd

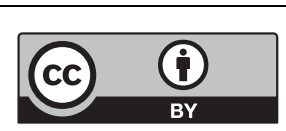

This work is licensed under a Creative Commons Attribution 4.0 International License. 
with congenital adrenal hyperplasia presents unique challenges $(3,4)$. Once growth is no longer a concern, a shift in treatment goals from optimization of growth and puberty to prevention of long-term adverse outcomes and optimization of fertility and sexual function is needed $(5,6,7,8,9,10)$.

The organization of transition is important in order to support and encourage these patients in this stressful period. The goal is also not to lose follow-up. However, very few studies have examined transitional care and its determinants in real life. Transition of care is a time when many patients with CAH stop adherence to their medication $(3,4,11)$. A German study insists on the lack of support concerning psychosexual development during transition period (4). Unfortunately, many patients in adulthood are lost to follow-up. An audit of transition of CAH patients in the United Kingdom showed that $50 \%$ of patients with $\mathrm{CAH}$ had poor biochemical control and/or adverse clinical consequences, and 50\% who were transferred to specialist adult services were lost to follow-up (12).

Health-related quality of life (QoL) in adult patients with $\mathrm{CAH}$ has been variously reported $(13,14,15)$. The reason for this heterogeneity in QoL reporting for $\mathrm{CAH}$ adults is debated but could relate to variables including treatment regimen, health care provision in different countries and genetics.

As there is no study evaluating the impact of transition on QoL and on the health status in CAH patients, we designed a study to evaluate the impact of a transition process and of a regular medical follow-up on QoL and on health status in a cohort of patients with classic and nonclassic CAH diagnosed during childhood.

\section{Patients and methods}

\section{Patients}

Patients were recruited from the registers of Pediatric departments belonging to the French reference center for endocrine rare disease (CRMERC), including 3 academic department of pediatric endocrinology located in Paris: Necker Hospital, Trousseau Hospital and Robert Debré Hospital. Patients were also recruited from the registers of the adult department of Endocrinology and Reproductive Medicine located in Pitié Salpêtrière Hospital. Ethical approval was granted by the Ethics Committee of Pitié-Salpêtrière Hospital (Paris, France). Consent has been obtained from each patient or subject after full explanation of the purpose and nature of all procedures used.

Inclusion criteria were adult patients born between 1970 and 1990; presence of classic or non-classic CAH diagnosed during childhood ( $<10$ years), according to the predicted severity of the mutations. Primary end point of the study was to compare the quality of life of adult $\mathrm{CAH}$ patients transitioned or not from pediatric care to specialist adult services. Secondary end points were comparison of adult height and difference compared to target height, body mass index (BMI), menstrual cycle regularity in women and plasma $17 \mathrm{OH}$-progesterone and renin concentrations in adult $\mathrm{CAH}$ patients with or without transition.

All patients eligible to enter this study were contacted by mail, e-mail or phone. In the event that no response was received, reminders were sent once, 3 months later. Again, in the event that no response was received, the general practitioner of the patient was contacted and recent address e-mail or phone was then used to contact the patient. In the absence of answer after this procedure, a letter with information notice of the study and WHOQOL was sent to the patient. Transition was defined by the transfer from pediatric care to specialist adult services, associated with the tailored transition program of each department. Regular follow-up was defined by the presence of 1 or more visits per year with an endocrinologist and without interruption period in this follow-up. All others were considered as not having gone through transition successfully.

\section{Study design}

All patients were seen early in the morning on the day of the visit for the study, and standard anthropometric measurements were obtained. BMI was calculated as weight/(height) ${ }^{2}\left(\mathrm{~kg} / \mathrm{m}^{2}\right)$. Data concerning presentation, diagnosis, medical treatment, conduct of a transition or not and other relevant information were reviewed. Regularity of menses was evaluated in women before the beginning of any therapy known to interfere with the menstrual cycle. The patients were divided into classic salt-wasting (SW) form, classic simple virilizing form (SV) and non-classic form according to the clinical data and the predicted severity of the mutations. All subjects fasted for at least $9 \mathrm{~h}$ before sampling. Blood samples for the measurement plasma $17 \mathrm{OH}$-progesterone were taken $1-2 \mathrm{~h}$ after administration of the morning medication. Samples were centrifuged and separated immediately after collection and were stored at $20^{\circ} \mathrm{C}$ until assayed.

This work is licensed under a Creative Commons Attribution 4.0 International License. 


\section{Quality of life}

The data collection instrument was the World Health Organization Quality of Life (WHOQOL)-BREF questionnaire, which is the summarized form of the comprehensive 100-question QoL measurement. It consists of 26 questions, scored on a 5-point Likert scale, which monitor different aspects of an individual's QoL. In this questionnaire, two questions were related to the patients' general feelings about their QoL. The remaining questions were related to the patients' feelings and behaviors during the previous 2 weeks in the physical dimension (physical activities, drug dependency and supportive medicines, mobility, pain and feeling of discomfort, sleep and rest and the ability to perform activities), psychological dimension (feeling toward body posture and appearance, positive and negative feelings, learning, thoughts, memory and concentration, self-confidence and personality traits), social dimension (personal relationships, social support) and environmental dimension (financial sources, freedom and physical security, accessibility to social and health care, house condition, accessibility to new data and various skills, opportunity to take part in social activities and physical environment such as pollution, noise, traffic and transportation). One question was related to the sexual dimension. Every question has a score range from 0 to 4; 0 represented the worst and 4 represented the best conditions of QoL. Achieved scores for each dimension were converted into a standardized form, ranging from 0 to 100 , following scoring instructions described in the manual of the WHO QoL-BREF questionnaire. This questionnaire has been validated in the French general population $(16,17)$.

\section{Statistical analysis}

All statistical analyses were performed using R software, version 2.11.1. A descriptive analysis of all patients was conducted. Results were reported as mean \pm s.D. (in case of normal distribution), or median (min; max) (in case of non-normal distribution) for continuous variables and as frequency counts and percentages (\%) for categorical variables. Characteristics of patients agreeing to participate (and thus included) in the study were first compared to those of patients who expressed a refusal (or did not answered) or were lost to follow-up.

A comparison was then performed among included patients according to whether they had a successful transition or not. In a subsequent exploratory analysis, we further examined the differences between patients with or without regular follow-up after their organized transition.

Chi-square or Fisher's exact tests were used to test for the association between categorical variables depending on expected frequencies. Differences in the distribution of continuous outcomes between two groups were investigated using Student $t$-tests or non-parametric Wilcoxon signed-rank tests (in case of non-normal distributions) were computed. For more than two groups, ANOVA tests or non-parametric Kruskal-Wallis tests were computed.

All tests used a two-sided significance level of 0.05 .

\section{Results}

\section{Population}

One hundred and eighty-three patients were eligible to participate in this study, 9 were excluded ( 8 had move abroad, 1 died (not related to $\mathrm{CAH}$ )). The CAH cohort was therefore 174 patients. Seventy-three patients agreed to take part in the study (42\%) (Fig. 1). The remaining 101 patients were either lost to follow-up $(n=48,28 \%)$ or declined the study or did not answer $(n=53,30 \%)$ (Fig. 1$)$. These 101 patients did not differ from the 73 studied patients in term of clinical or hormonal presentation, except for the age at the end of the study $(34.8 \pm 5.5$ years for the group lost to follow-up, $31.7 \pm 5.7$ years for the group who refuse to participate and $32.7 \pm 6.2$ years for patients included, $P=0.02$ ) (Table 1 ). Patients included in the study were less frequently salt-wasters (48 vs $75 \%$ for the group lost to follow-up and 61\% for the group who refuse to participate). Transition program was proposed to $80 \%$ of the patients included in the study, $35 \%$ of the patients lost to follow-up and $64 \%$ of the patients, which refuse to participate (Table 1 ).

Among the 73 patients included in the study, 59 were transferred to specialist adult services by their pediatricians for transition. Among them, 48/59 had a regular medical follow-up in adulthood (Fig. 1). Among the 14 patients not transferred to specialist adult services, only one had a regular medical follow-up in adulthood (Fig. 1).

\section{QoL results}

$\mathrm{CAH}$ patients were compared regarding the existence or not of a transfer to adult specialist services (patients with or without transition, Table 2). There was less http://www.endocrineconnections.org DOI: 10.1530/EC-17-0094
() 2017 The authors Published by Bioscientifica Ltd

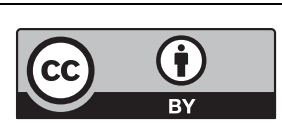

This work is licensed under a Creative Commons Attribution 4.0 International License. 


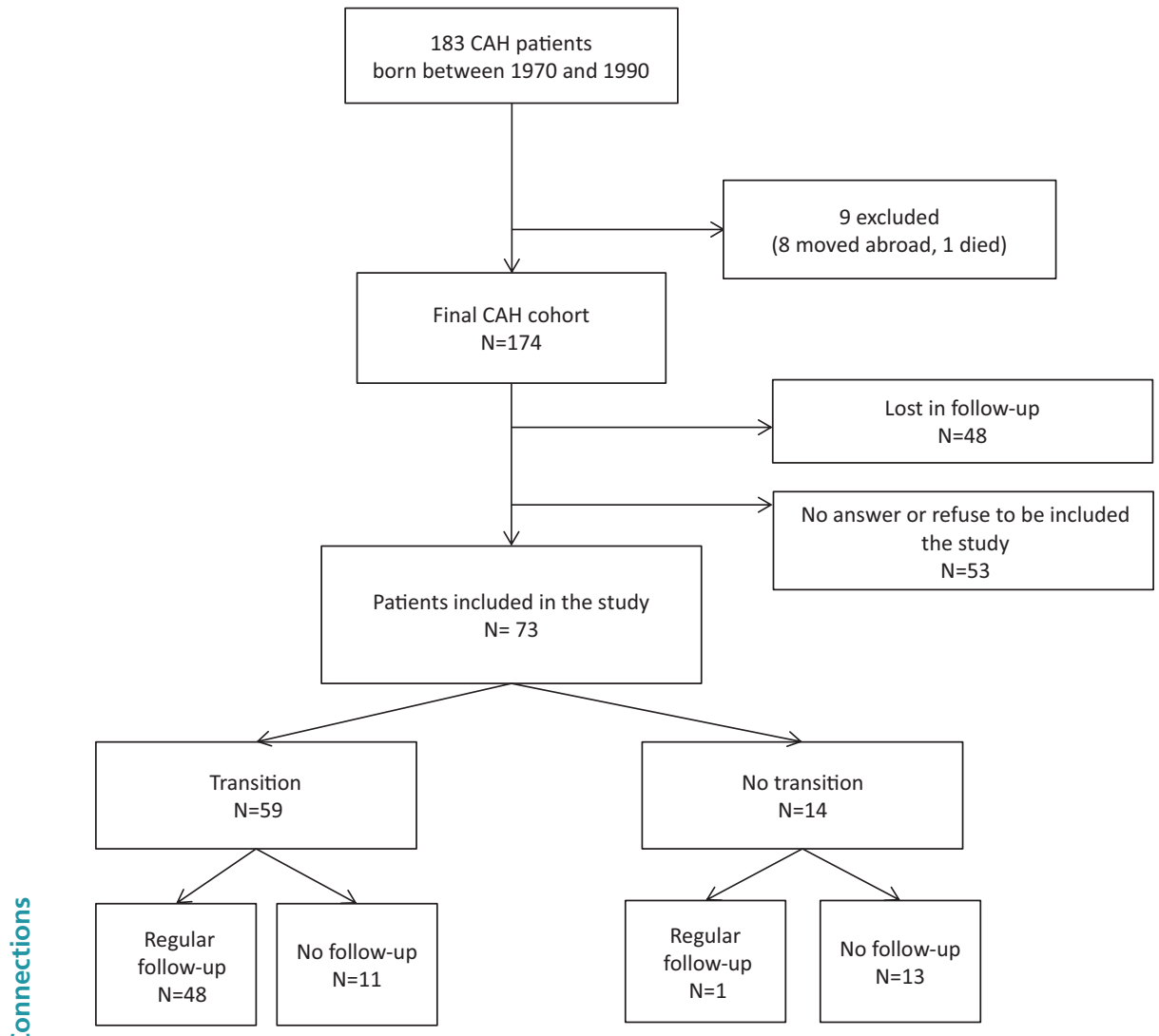

Figure 1

CAH patients included in the study.

women in the group with transition, even though it did not reach the significant level. Patients with transition were younger than the other group $(P=0.02)$ and were more frequently presenting SW CAH (32/59 patients with transition vs $3 / 14$ without transition, $P=0.03$ ) (Table 2 ). WHOQOL-BREF scores were generally similar between groups, except for environment dimension score, which was slightly higher in CAH patients without transition $(P=0.01$, Table 2).

Successful transition was defined by regular follow-up of patients after the transfer to adult specialist services. This allowed us to analyze not only the impact of a transition but also the real impact of a successful transition on the QoL and on clinical and hormonal

Table 1 Clinical characteristics of the CAH patients eligible to the study.

\begin{tabular}{|c|c|c|c|c|}
\hline & Included $(n=73)$ & Lost to follow-up $(n=48)$ & Refuse to participate $(n=53)$ & $P$ \\
\hline \multicolumn{5}{|l|}{ Gender } \\
\hline Women & 48 & 34 & 34 & 0.76 \\
\hline Form of $\mathrm{CAH}$ & & & & 0.09 \\
\hline \multicolumn{5}{|l|}{ Classic } \\
\hline Simple virilizing form & 15 & 4 & 6 & \\
\hline Salt-wasting & 35 & 27 & 30 & \\
\hline Non-classic & 23 & 5 & 13 & \\
\hline Age at diagnosis & $0.5(0.0 ; 14.0)$ & $0.00(0.0 ; 8.0)$ & $0.00(0.0 ; 9.0)$ & 0.09 \\
\hline Prader classification (women) & & & & 0.07 \\
\hline Normal & 19 & 3 & 6 & \\
\hline | ou || & 6 & 4 & 3 & \\
\hline III ou IV & 18 & 16 & 17 & \\
\hline \multicolumn{5}{|l|}{ Finale height $(\mathrm{cm})$} \\
\hline Women & $157.0 \pm 6.8$ & $154.0 \pm 8.7$ & $159.2 \pm 6.0$ & 0.12 \\
\hline Men & $168.4 \pm 6.6$ & $171.6 \pm 6.7$ & $168.9 \pm 7.1$ & 0.64 \\
\hline Age at the end of the study (years) & $33(24 ; 44)$ & $34(25 ; 44)$ & $30(24 ; 43)$ & 0.02 \\
\hline Organized transition process & 59 & 17 & 34 & 0.30 \\
\hline $\begin{array}{l}\text { http://www.endocrineconnections.org } \\
\text { DOI: 10.1530/EC-17-0094 }\end{array}$ & $\begin{array}{r}\text { @ } 2017 \text { The } \\
\text { Published by Bioscient }\end{array}$ & & $\begin{array}{l}\text { This work is licensed under a Creat } \\
\text { Attribution } 4.0 \text { International Licen }\end{array}$ & ommons \\
\hline
\end{tabular}


Table 2 Clinical characteristics of the CAH patients and results of WHOQOL-BREF according to transition

Gender
Women
Form of CAH
Classic
Simple virilizing form
Salt wasting
Non-classic
Age at diagnosis (years)
Age at inclusion (years)
Way of life
Single
In couple
Live with parents
WHOQOL-BREF
Dimensions
Physical health
Psychological health
Social relationships
Environment
Items
Global quality of life
Global health

\begin{tabular}{c}
\hline Patients with transition $(n=59)$ \\
36 \\
9 \\
32 \\
18 \\
$0.0(0 ; 14)$ \\
$30.0(23 ; 43)$ \\
15 \\
26 \\
18 \\
\\
$67.9(39.3 ; 85.7)$ \\
$62.5(16.7 ; 83.3)$ \\
$75.0(8.3 ; 100.0)$ \\
$75.0(28.1 ; 100.0)$ \\
$4.0(2.0 ; 5.0)$ \\
$4.0(1.0 ; 5.0)$
\end{tabular}

\begin{tabular}{|c|c|}
\hline Patients without transition $(n=14)$ & $P$ \\
\hline 12 & $\begin{array}{l}0.12 \\
0.03\end{array}$ \\
\hline $\begin{array}{l}6 \\
3 \\
5\end{array}$ & \\
\hline $\begin{array}{c}1.0(0 ; 10) \\
36.0(25 ; 43) \\
7 \\
5 \\
2\end{array}$ & $\begin{array}{l}0.70 \\
0.02 \\
0.11\end{array}$ \\
\hline $\begin{array}{r}71.4(50.0 ; 89.3) \\
60.40(29.2 ; 83.3) \\
70.8(8.3 ; 100.0) \\
79.6(68.8 ; 96.9)\end{array}$ & $\begin{array}{l}0.11 \\
0.66 \\
0.87 \\
0.01\end{array}$ \\
\hline $\begin{array}{r}4.00(2.0 ; 5.0) \\
4.0(2.0 ; 5.0)\end{array}$ & $\begin{array}{l}0.22 \\
0.26\end{array}$ \\
\hline
\end{tabular}

parameters (Table 3). The only difference between the two groups was the repartition of gender: less women were lost to follow-up after transition process (33/36 women had a regular follow-up vs $15 / 23$ men, $P=0.02$ ). CAH patients with a successful transition had a better physical health, psychological health and environment score and item global QoL than the group without regular follow-up after transition (Table 3). There was no difference between the two groups regarding patient's level of education. Nevertheless, regarding socioeconomic status, patients with regular follow-up were more frequently managerial $(10 / 48$ vs $1 / 11)$ or intermediate $(10 / 48 \%$ vs $0 / 11)$.
Unfortunately, multivariate analysis or adjusted results could not be performed due to the low sample size.

\section{Secondary end points}

Secondary end points were only available for 49 patients. Patients with transition $(n=39$, among them 32 with regular follow-up) were compared to patients without transition ( $n=10$, none with regular follow-up). There were 25 women among the 39 patients with transition, and 9 women among the 10 patients without transition $(P=0.14)$. Adult height was the same between the women

Table 3 Clinical characteristics and results of WHOQOL-BREF of CAH patients with or without successful transition.

\begin{tabular}{|c|c|c|c|}
\hline & Regular follow-up after transition $(n=48)$ & No regular follow-up after transition $(n=11)$ & $P$ \\
\hline Gender & & & 0.02 \\
\hline Women & 33 & 3 & \\
\hline Form of $\mathrm{CAH}$ & & & 0.53 \\
\hline \multicolumn{4}{|l|}{ Classic } \\
\hline Simple virilizing form & 8 & 1 & \\
\hline Salt-wasting & 24 & 8 & \\
\hline Non-classic & 16 & 2 & \\
\hline Age at inclusion (years) & $30.0(23.0 ; 43.0)$ & $33.0(23.0 ; 43.0)$ & 0.66 \\
\hline \multicolumn{4}{|l|}{ WHOQOL-BREF } \\
\hline \multicolumn{4}{|l|}{ Dimensions } \\
\hline Physical health & $69.6(42.9 ; 85.7)$ & $57.0(39.3 ; 75.0)$ & 0.03 \\
\hline Psychological health & $65.0(41.7 ; 83.3)$ & $50.0(16.7 ; 64.6)$ & 0.01 \\
\hline Social relationships & $75.0(8.3 ; 100.0)$ & $66.7(8.3 ; 91.7)$ & 0.11 \\
\hline Environment & $78.1(34.4 ; 100.0)$ & $62.5(28.1 ; 84.4)$ & 0.04 \\
\hline \multicolumn{4}{|l|}{ Items } \\
\hline Global quality of life & $4.0(3.0 ; 5.0)$ & $4.0(2.0 ; 5.0)$ & 0.02 \\
\hline Global health & $4.0(2.0 ; 5.0)$ & $4.0(1.0 ; 5.0)$ & 0.21 \\
\hline $\begin{array}{l}\text { http://www.endocrineconnections.org } \\
\text { DOI: } 10.1530 / \text { EC-17-0094 }\end{array}$ & $\begin{array}{r}\odot 2017 \text { The authors } \\
\text { Published by Bioscientifica Ltd }\end{array}$ & $\begin{array}{l}\text { This work is licensed under a Creative } \\
\text { Attribution } 4.0 \text { International License. }\end{array}$ & Imons \\
\hline
\end{tabular}


in the two groups $(1.57 \mathrm{~m}(1.45 ; 1.70)$ vs $1.57 \mathrm{~m}(1.38$; $1.67), P=0.68)$. BMI did not differ between the two groups $\left(25.1 \mathrm{~kg} / \mathrm{m}^{2}(18.3 ; 47.6) \mathrm{vs} 25.1 \mathrm{~kg} / \mathrm{m}^{2}(21 ; 38.5), P=0.74\right)$. Menstrual cycles were regular for around two thirds of the patients in each group. There was no difference between $17 \mathrm{OH}$-progesterone and renin concentrations between the two groups $(12.8(0.8 ; 193.0) \mathrm{ng} / \mathrm{mL}$ vs $8.9(0.5 ; 133) \mathrm{ng} / \mathrm{mL}$, $P=0.32$ and $19.0 \mathrm{pg} / \mathrm{mL}(0.3 ; 248.7)$ vs $14.3 \mathrm{pg} / \mathrm{mL}(6.4$; 61.9), $P=0.32$ respectively).

\section{Discussion}

Much emphasis has recently been placed on the importance of transitional care for chronic nonendocrine and endocrine diseases in childhood; however, very few studies have examined transitional care and its determinants (18). Improving transition from pediatric to adult endocrine care is a recognized challenge. Although there is emerging evidence about how to organize transition, there is a need to identify which patients are at risk of drifting away from endocrine care and to evaluate the impact of a successful transition (12). A recent study in the United Kingdom, however, estimated the numbers of patients with $\mathrm{CAH}$ attending specialist adult services between 2 and 5\%. Inadequate transition to adult services was emphasized as a potential explanation (7). An assessment of a single centre's experience of transitioning patients with $\mathrm{CAH}$ to specialist adult services has highlighted that the difficulty of a good health status at transfer and engagement with adult services (12). In this audit, $50 \%$ of patients with $\mathrm{CAH}$ had poor biochemical control and/or adverse clinical consequences, and 50\% who were transferred to specialist adult services were lost to follow-up (12). Introduction of young person clinic increased the numbers of patients being transferred to specialist adult services but failed to improve engagement (12). In our study, we confirmed these data, as almost a third of the CAH patients were lost to follow-up in adulthood, despite a regular care in tertiary medical center during childhood. We also demonstrated that transition was closely linked to regular medical care during adulthood. It reinforces the concept of a well-organized transition $(3,7,12)$. Indeed, in this paper, transition was defined by the transfer from pediatric care to specialist adult services, associated with the tailored transition program of each department, and these programs are in constant evolution and evaluation (19).

Health-related quality of life (QoL) in adult patients with CAH has been variously reported $(13,14,15,20$,
$21,22)$. Three groups have reported better, similar or mildly impaired QoL in CAH patients compared with controls or the normal population $(14,15,20)$, while other publications have reported poor QoL in CAH adults $(13,21,22,23,24)$. The reason for this heterogeneity in QoL reporting for CAH adults is still debated but could relate to variables including treatment regimen, health care provision in different countries and genetics, but seems not related to genotype (severity of the mutations) or phenotype (classic or non-classic). Our study on a large cohort of $\mathrm{CAH}$ adults is the first to report on the impact of transition and specialist medical care on QoL. We found that global QoL was not different in patients with or without transition but was better in adult CAH patients with regular medical follow-up and a successful transition. We had previously reported on the evaluation of the transition process and on the needs expressed by patients with chronic endocrine conditions at transition (19). This earlier pilot study involving $13 \mathrm{CAH}$ patients has shown that the vast majority of subjects had a good knowledge of their medication. Patients were also asked at the initial visits whether specific medical concerns about adult $\mathrm{CAH}$ had been properly addressed. Most women (67\%) and all men were satisfied with the information received about fertility and genetic transmission to offspring (19).

Limitations in this study include its cross-sectional nature, the loss to follow-up and the large number of variables examined. Indeed, as 101/174 patients were not included in the study, we have no information about most of the patients, which is a general problem with studies of CAH adults. We cannot fully exclude that the 14 subjects who did not undergo successful transition belong to a special group of patients prone to decreased QoL and reluctant to undergo adult follow-up in a specialized adult department. Moreover, patients with regular follow-up belonged to a higher socioeconomic class, which could impact on the results of QoL; however, due to the low sample size, this hypothesis could not be tested, as multivariate analysis or adjusted results could not be performed. Future prospective studies designed specifically to examine the long-term effects of a successful transition $\mathrm{CAH}$ patients are needed to address the limitations of this study.

Impact of a successful transition on future health status is not known. In this study, we could not highlight a difference between the different groups regarding comorbidity described in $\mathrm{CAH}$ patients, i.e. BMI, and reproductive function in women. This could be explained by the reduced number of patients included

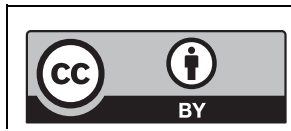

This work is licensed under a Creative Commons Attribution 4.0 International License. 
in this secondary analysis, as the study and the number of patients included were not designed to demonstrate it. Longitudinal studies have to answer more precisely these questions.

In conclusion, regular medical follow-up in adulthood is closely related to the transition between pediatric and adult care and is associated with better QoL in adults with CAH. The ideal conditions of pediatric to adult care transition, associated with training, counseling and education and the medical consequences of a successful transition have to be further studied.

\section{Declaration of interest}

The authors declare that there is no conflict of interest that could be perceived as prejudicing the impartiality of the research reported.

\section{Funding}

Funding for this study was provided by a grant from the Pfizer Foundation.

\section{Acknowledgements}

CRMERC study group: Dr Claire Bricaire, Dr Mireille Castanet, Pr Jacques Young, Pr Sophie Christin-Maitre, Dr Anne Claire Bouthillier-Voisin, Dr Carine Courtillot, Dr Jacques Allouche, Dr Laurence Ritz Quillacq, Pr Thierry Brue, Dr Thibault Richard, Dr Isabelle Raingeard, Dr Thierry Godeau, Pr Philippe Caron, Pr Michel Pugeat, Dr Françoise Galland, Dr Florence Torremocha, Dr Elisabeth Requeda, Dr Marie Charles Raux Demay, Dr Yves Boutonnat, Dr Jihad Samrani, Dr Laurence Bernard, Pr Marie-Charles Raux Demay, Dr Albert David, Dr Dinane SamaraBoustani, Dr Christine Boissinot, Pr Eric Mallet, Dr Christian Pauwels, Pr Paul Czernichow, Dr Antoine Leblanc, Pr Irène Netchine, Dr Hélène Crosnier, Pr Raphael Rappaport, Dr Blandine Esteva, Pr Jean-Claude Carel, Dr Graziella Pinto, Pr Juliane Leger, Dr Sabine Baron, Dr Gourmelen.

\section{References}

1 Blum RW, Garell D, Hodgman CH, Jorissen TW, Okinow NA, Orr DP \& Slap GB. Transition from child-centered to adult health-care systems for adolescents with chronic conditions. A position paper of the Society for Adolescent Medicine. Journal of Adolescent Health 1993 14 570-576. (doi:10.1016/1054-139X(93)90143-D)

2 Merke DP \& Bornstein SR. Congenital adrenal hyperplasia. Lancet 2005365 2125-2136. (doi:10.1016/S0140-6736(05)66736-0)

3 Merke D \& Poppas DP. Management of adolescents with congenital adrenal hyperplasia. Lancet Diabetes and Endocrinology 20131 341-352. (doi:10.1016/S2213-8587(13)70138-4)

4 Kruse B, Riepe FG, Krone N, Bosinski HA, Kloehn S, Partsch CJ, Sippell WG \& Mönig H. Congenital adrenal hyperplasia - how to improve the transition from adolescence to adult life. Experimental Clinical Endocrinology and Diabetes 2004112 343-355. (doi:10.1055/s-2004-821013)

5 Ogilvie CM, Crouch NS, Rumsby G, Creighton SM, Liao LM \& Conway GS. Congenital adrenal hyperplasia in adults: a review of medical, surgical and psychological issues. Clinical Endocrinology 2006 64 2-11. (doi:10.1111/j.1365-2265.2005.02410.x)

6 Bachelot A, Golmard JL, Dulon J, Dahmoune N, Leban M, Bouvattier C, Cabrol S, Leger J, Polak M \& Touraine P. Determining clinical and biological indicators for health outcomes in adult patients with childhood onset of congenital adrenal hyperplasia. European Journal of Endocrinology 2015173 175-184. (doi:10.1530/EJE-14-0978)

7 Arlt W, Willis DS, Wild SH, Krone N, Doherty EJ, Hahner S, Han TS, Carroll PV, Conway GS, Rees DA, et al. United Kingdom congenital adrenal hyperplasia adult study executive (CaHASE): health status of adults with congenital adrenal hyperplasia: a cohort study of 203 patients. Journal of Clinical Endocrinology and Metabolism 201095 5110-5121. (doi:10.1210/jc.2010-0917)

8 Finkielstain GP, Kim MS, Sinaii N, Nishitani M, Van Ryzin C, Hill SC, Reynolds JC, Hanna RM \& Merke DP. Clinical characteristics of a cohort of 244 patients with congenital adrenal hyperplasia. Journal of Clinical Endocrinology and Metabolism 201297 4429-4438. (doi:10.1210/jc.2012-2102)

9 Falhammar H, Frisén L, Hirschberg AL, Norrby C, Almqvist C, Nordenskjöld A \& Nordenström A. Increased cardiovascular and metabolic morbidity in patients with 21-Hydroxylase deficiency: a Swedish population-based national cohort study. Journal of Clinical Endocrinology and Metabolism 2015100 3520-3528. (doi:10.1210/JC.2015-2093)

10 Bouvattier $C$, Esterle L, Renoult-Pierre $P$, de la Perrière $A B$, Illouz F, Kerlan V, Pascal-Vigneron V, Drui D, Christin-Maitre S, Galland F, et al. Clinical outcome, hormonal status, gonadotrope axis, and testicular function in 219 adult men born with classic 21-Hydroxylase deficiency. A French national survey. Journal of Clinical Endocrinology and Metabolism 2015100 2303-2313. (doi:10.1210/jc.2014-4124)

11 Auchus RJ, Witchel SF, Leight KR, Aisenberg J, Azziz R, Bachega TA, Baker LA, Baratz AB, Baskin LS, Berenbaum SA, et al. Guidelines for the development of comprehensive care centers for congenital adrenal hyperplasia: guidance from the CARES foundation initiative. International Journal of Pediatric Endocrinology 20102010 275213. (doi:10.1186/1687-9856-2010-275213)

12 Gleeson H, Davis J, Jones J, O'Shea E \& Clayton PE. The challenge of delivering endocrine care and impact of transition on adult service on quality of life in patients with congenital adrenal hyperplasia: experience in a single centre over 18 years. Clinical Endocrinology 2013 78 23-28. (doi:10.1111/cen.12053)

13 Han TS, Krone N, Willis DS, Conway GS, Hahner S, Rees DA, Stimson RH, Walker BR, Arlt W \& Ross RJ. United Kingdom congenital adrenal hyperplasia adult study executive (CaHASE): quality of life in adults with congenital adrenal hyperplasia relates to glucocorticoid treatment, adiposity and insulin resistance: United Kingdom congenital adrenal hyperplasia adult study executive (CaHASE). European Journal of Endocrinology 2013168 887-893. (doi:10.1530/EJE-13-0128)

14 Jääskeläinen N \& Voutilainen R. Long-term outcome of classical 21-hydroxylase deficiency: diagnosis, complications and quality of life. Acta Paediatrica 200089 183-187. (doi:10.1111/j.1651-2227.2000.tb01213.x)

15 Reisch N, Hahner S, Bleicken B, Flade L, Pedrosa Gil F, Loeffler M, Ventz M, Hinz A, Beuschlein F, Allolio B, et al. Quality of life is less impaired in adults with congenital adrenal hyperplasia because of 21-hydroxylase deficiency than in patients with primary adrenal insufficiency. Clinical Endocrinology $2011 \mathbf{7 4}$ 166-173. (doi:10.1111/j.1365-2265.2010.03920.x)

16 Baumann C, Erpelding ML, Régat S, Collin JF \& Briançon S. The WHOQOL-BREF questionnaire: French adult population norms for the physical health, psychological health and social relationship dimensions. Revue d'Épidémiologie et de Santé Publique 201058 33-39. (doi:10.1016/j.respe.2009.10.009)

17 World Health Organization. WHOQOL-BREF: Introduction, Administration, Scoring and Generic Version of the Assessment: Field Trial Version, December 1996. Geneva, Switzerland: WHO, 1996. (available at: http://www.who.int/mental_health/media/en/76.pdf)

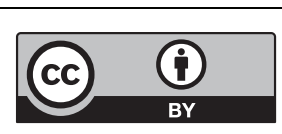

This work is licensed under a Creative Commons Attribution 4.0 International License. 
18 Devernay M, Ecosse E, Coste J \& Carel JC. Determinants of medical care for young women with Turner syndrome. Journal of Clinical Endocrinology and Metabolism 200994 3408-3413. (doi:10.1210/jc.2009-0495)

19 Kuhnle U, Bullinger M \& Schwarz HP. The quality of life in adult female patients with congenital adrenal hyperplasia: a comprehensive study of the impact of genital malformations and chronic disease on female patients life. European Journal of Pediatrics 1995154 708-716. (doi:10.1007/BF02276713)

20 Han TS, Conway GS, Willis DS, Krone N, Rees DA, Stimson RH, Arlt W, Walker BR \& Ross RJ. United Kingdom congenital adrenal hyperplasia adult study executive (CaHASE): relationship between adult height and health outcomes in adults with congenital adrenal hyperplasia: United Kingdom congenital adrenal hyperplasia adult study executive (CaHASE). Journal of Clinical Endocrinology and Metabolism 201499 E1547-E1555. (doi:10.1210/jc.2014-1486)
21 Johannsen TH, Ripa CPL, Mortensen EL \& Main KM. Quality of life in 70 women with disorders of sex development. European Journal of Endocrinology 2006155 877-885. (doi:10.1530/eje.1.02294)

22 Nermoen I, Husebye ES, Svartberg J \& Løvås K. Subjective health status in men and women with congenital adrenal hyperplasia: a population-based survey in Norway. European Journal of Endocrinology 2010163 453-459. (doi:10.1530/EJE-10-0284)

23 Nordenskjöld A, Holmdahl G, Frisén L, Falhammar H, Filipsson H, Thorén M, Janson PO \& Hagenfeldt K. Type of mutation and surgical procedure affect long-term quality of life for women with congenital adrenal hyperplasia. Journal of Clinical Endocrinology and Metabolism 200893 380-386. (doi:10.1210/jc.2007-0556)

24 Godbout A, Tejedor I, Malivoir S, Polak M \& Touraine P. Transition from pediatric to adult healthcare: assessment of specific needs of patients with chronic endocrine conditions. Hormone Research in Paediatric 201278 247-255. (doi:10.1159/000343818)

Received in final form 12 July 2017

Accepted 18 July 2017

Accepted Preprint published online 18 July 2017 http://www.endocrineconnections.org DOI: 10.1530/EC-17-0094 (c) 2017 The authors Published by Bioscientifica Ltd

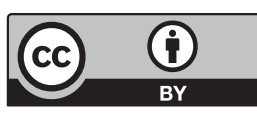

This work is licensed under a Creative Commons Attribution 4.0 International License. 